\title{
Cytoprotective Effect of Zingiber Officinale extract on Alcohol Induced Gastric Lesion in Mice
}

\author{
Samia Elzwi ${ }^{1 *}$ and Amina Elzwi ${ }^{2}$ \\ ${ }^{1}$ MSc Lecture at pharmacology department, University of Benghazi, Libya \\ ${ }^{2}$ Pharmacy doctor at faculty of pharmacy, University of Benghazi, Libya
}

*Corresponding author: Samia Elzwi, MSc Lecture at pharmacology department, University of Benghazi, Libya

\begin{abstract}
Ginger is a perennial plant that grows in India, China, Mexico and several other countries. The rhizome is used as both spice and in herbal medicine. Many studies have been done on pharmacological effect of ginger extract and our paper has been focused on cytoprotective effect of ginger on ethanol induced gastric injury in mice. Many drugs have been used in the treatment of peptic ulcer but each of them associated with different side effect so trends today toward use of herbal medicine which was associated with adverse effect. Ginger hydroalcoholic extract contain different consistent with anti-ulcer properties like 6-Gingersulfonic acid and three monoacyldigalactosyl glycerol including ginger glycolipid A. B. C.The mechanism of ginger extract may be due to counteracting the active oxidant radicals, decreasing mucosal cell shedding and thicking the mucus membrane so ginger extract has antiulcer properties when used in accurate dose and accurate duration.
\end{abstract}

Keywords: Cytoprotective effect; Ethanol; Ginger hydroalcoholic extract; Mice; Zingiber Officinale

\section{Introduction}

Spices, the predominant flavoring, coloring, and aromatic agents in food and beverages are now gaining importance for their diversified uses. Ginger (Zingiber Officinale) is a medicinal plant that has been widely used in Chinese, and Tibb Unani herbal medicines all over the world, since antiquity, for a wide array of unrelated ailments that include muscular aches, sore throat, constipation, arthritis, indigestion, vomiting and infectious diseases. Currently, there is a renewed interest in ginger, and several scientific investigations aimed at isolation and identification of active constituents of ginger, scientific verification of its pharmacological actions and of its constituents, and verification of the basis of the use of ginger in several diseases and conditions Ali et al. [1].

Ginger grows best in tropical and subtropical areas, which have good rainfall with hot and humid conditions during the summer season. It is a member of Zingiberaceae family originated in Southeast Asia and has been introduced to many parts of the globe where it proliferates in suitable environment. Belief in the medicinal properties of ginger existed in ancient Indian and oriental cultures where ginger has been used alone or as a component in herbal remedies. This practice continues today in many areas of the world including Africa, Brazil, China and, Mexico. Ginger has introduced to Europe and other areas by Dutch, Portuguese Arab and Spanish explorers or traders from around the $13^{\text {th }}$ to $16^{\text {th }}$ centuries.

\section{Carbohydrates}

Starch is the major constituent up to $50 \%$.

\section{Oleoresin}

Gingerol homologues (major, about 33\%) include derivatives with methyl side chain, shogaol homologues (dehydration products of gingerols), zingerone (degradation product of gingerols) ,1dehydrogingerdione and 6- ginger sulfonic acid.

\section{Lipids 6-8\%}

They include free fatty acids e.g. palmitic acid, oleic acid, linoleic acid, caprylic acid, capric acid, lauric acid, myristic acid, pentadecanoic acid, heptadecanoic acid, stearic acid, linolenic acid, arachidonic acid, triglycerides, phosphatidic acid, lecithin and ginger glycolipids A, B and C. Ulcer are caused due to imbalance between aggressive factors (hydrochloric acid, pepsin, gastrin, no 
steroidal anti-inflammatory drugs, and ethanol) and defensive factor of gastric mucosa (prostaglandin, mucus, bicarbonate). The antiulcerogenic activity of many plant products is reported due to an increase in mucosal defensive factors rather than decrease in the aggressive factors Goel, et al. [2]. Numbers of an antiulcer drugs like gastric antisecretory drugs $\mathrm{H} 2$ - receptor antagonist, antimuscarinic agents, proton pump inhibitors, and mucosal protective agents, carbenoxolone sodium, sucralfate, and prostaglandin analogous are available which are shown to have side effects and limitation Baowman et al. [3].

There are several herbal ayuvedic preparation which have a protective effect against gastric mucosal injury Shetty et al. [4]. Herbal medicine is now used by up to $50 \%$ of the Western population in a number of instances $10 \%$ for treatment or prevention of digestive disorders Langmead and Rampton [5]. Today, pharmacopoeias of a number of different countries list ginger extract for various digestive disease, Aromatic, spasmolytic and carminative properties of ginger are probably responsible for the therapeutic application in digestive tract ailments Sertie et al. [6].

\section{Mechanism of Gastric Effect of Ginger}

Several studies have shown that ginger extract, essential oils and glycolipids possess a number of pharmacological actions, which at least in part for some of them anti-ulcerogenic or ulcer preventive efficacy may be suggested. Common side effects of treating inflammation with modern drugs is that ulcer in the digestive system can be created or their condition made worse Wallace [7]. Ginger not only relieves the symptoms of inflammation but also protects the creation of digestive ulcers. Ginger may protect the stomach from the damaging effect of alcohol and non- steroidal anti-inflammatory drugs and may help prevent ulcers Villegas et al. [8]. A study was done in Isfahan university by Miniaiyan et al. [9] for anti-ulcerogenic effect of ginger on cysteamine-induced duodenal ulcer in rats. The results obtained in positive control groups indicated that ginger possesses its anti-ulcerative properties through a mechanism mainly related to acid- pepsin inhibition.

The effect of ginger (acetone extract) and zingiberene on hydrochlochloric acid/ethanol-induced gastric lesions in rats have been examined (6)- gingerol and zingiberene, both $100 \mathrm{mg} /$ $\mathrm{kg}$ oral), significantly inhibited gastric lesions by $54.5 \%$ and $53.6 \%$ respectively. The total extract inhibited lesions by $97.5 \%$ at $1 \mathrm{~g} / \mathrm{kg}$. Oral administration of both aqueous and methanol ginger extract to rabbit has been reported to reduce gastric secretions (gastric juice volume, acid and pepsin output). Both extracts were found to be comparable with cimetidine $(50 \mathrm{mg} / \mathrm{kg}$ ) with respect to gastric juice volume.

The aqueous extract was comparable with cimetidine and superior to the methanol extract for pepsin output, and the methanol extract superior to the aqueous extract and comparable to cimetidine for acid output. Roasted ginger decoction which showed an obvious inhibiting tendency on three gastric ulcer models. The plant contains active materials which for some of them ulcer protective properties have been identified 6- ginger sulfonic acid and three monoacyldigalactosyl glycerols including ginger glycolipid A,B,C have been isolated from dried rhizome of Zingiber Officinale which are potent anti-ulcer components Yoshikawa et al. [10].

a) 6- gingerol and 6- shagaol are two other anti-ulcer components that are less potent nut are mainly responsible for ginger pungency.

b) Results of one study fore effects of three herbal medicine including Zingiber Officinale on gastric ulceration and secretion in rats indicated significant protection against stress, aspirin and pylorus ligation. The proposed anti-ulcerogenic effects were augmentation of mucin secretion and decrease in cell shedding.

c) Al-Yahya et al. [11] Studied the cytoprotective and gastric anti-ulcer effect of ginger in albino rats. Cyto destruction was produced by $80 \%$ ethanol, $0.6 \mathrm{M} \mathrm{HCL}, 0.2 \mathrm{M} \mathrm{NaOH}$ and 25\% Nacl. Gastric ulcer was produced by ulcerogenic agents including indomethacin, aspirin and reserpine beside hypothermic restraint stress and by pylorus ligation. The results of this study demonstrated that the extract in the dose $500 \mathrm{mg} / \mathrm{kg}$ orally exerted highly significant cryoprotection and prevented occurrence of gastric ulcers induced by non- steroidal antiinflammatory drugs.

\section{Method}

Experimental animals: Albino mice of either sex weighing 20$30 \mathrm{~g}$, was maintained in the animal house of Faculty of MedicineAl Arab Medical University, Benghazi, Libya the mice were bred in the faculty animal house. All animals were housed in standard polypropylene cages $(48 \times 35 \times 22 \mathrm{~cm})$ and kept under controlled room temperature. $\left(20 \pm 5{ }^{\circ} \mathrm{C}\right.$; relative humidity $\left.60-70 \%\right)$ in a $12 \mathrm{~h}$ light-dark cycle.

The animals were given a standard laboratory diet and free water Food was withdrawn $12 \mathrm{~h}$ before and during the experimental hours:

\section{Maceration method}

In this method fresh ginger rhizome was cut into small pieces, dried, and then pulverized into coarse powder and weighing about $400 \mathrm{~g}$ of powder. It was macerated in $1000 \mathrm{ml}$ hydroalcoholic solution (70\% Ethanol, 30\% distilled water) for seventy-two hours. The extract was then shaked, filtered by using dryness filter paper and the solution was evaporated in a rotatory evaporator under reduced pressure until evaporation and removal of the solvent give hydroalcoholic extract of ginger out of $400 \mathrm{~g}$ of crude plant, $8 \mathrm{~g}$ of hydroalcoholic extract of ginger were obtained and kept for use 
in pharmacological experiments (Iranian Herbal Pharmacopeia). Study of cytoprotective effect of Zingiber (ginger) extract on ethanol-induced gastric lesion in mice.

The present paper was designed to investigate the cytoprotective effect of hydroalcoholic extract of ginger in an animal model of gastric lesion. Mice of either sex weighing 25-30g were employed in this study the animals were divided isoups each consisting of six mice.

1. Normal group: Given vehicle $(5 \mathrm{ml} / \mathrm{kg}$ orally) without ulcer induction.

2. Control group: Given vehicle $(5 \mathrm{ml} / \mathrm{kg}$ orally) one hour before ulcer induction.

3. Extract group: Given hydroalcoholic extract of ginger in a dose (300mg/kg orally) one hour before ulcer induction.

4. Extract group: Given hydroalcoholic extract of ginger in a dose of $(600 \mathrm{mg} / \mathrm{kg}$ I.P) one hour before ulcer induction.

5. Chronic extract group: Given hydroalcoholic extract of ginger. In a dose of $(300 \mathrm{mg} / \mathrm{kg}$ I.P) for five consecutive days before ulcer induction. The last dose was administered one hour before ulcer induction.
6. Reference group: Given rantidine (50mg/kg I.P) one hour before ulcer induction.

One hour after intragastric administration of absolute ethanol (95\%, 0.2 $\mathrm{ml})$, the animals are euthanized with ether, the stomach were excised, cut along the greater curvature, and gently rinsed under tap water, and examined by 5 -fold binocular magnifier to assess lesion in gastric mucosa.

\section{Results}

As shown in Figure 1 normal gastric mu cosa Figure [A] compared with Figure [B \& C] with treatment by ethanol there is exfoliation and sloughing of gastric cells with inflammatory cell infiltrate and congestion of blood vessels Figure [D]. Figure 2 shows partial improvement in gastric lesion in the group treated by oral ginger treatment at dose $300 \mathrm{mg} / \mathrm{kg}$ as there is mild exfoliation of gastric cells Figure [A]. Moderate gastric protection by (I.P) treatment of ginger at a dose $600 \mathrm{mg} / \mathrm{kg}$ as there is moderate exfoliation of gastric cells as shown in Figure [B]. Complete protection by chronic (I.P) treatment of ginger in a dose of $300 \mathrm{mg} / \mathrm{kg}$ with no exfoliation of gastric cells as shown in Figure [C]. Rantidine has moderate protective effect as shown in Figure [D] compared with extract in Figure [C] with complete protection of gastric mucosa.
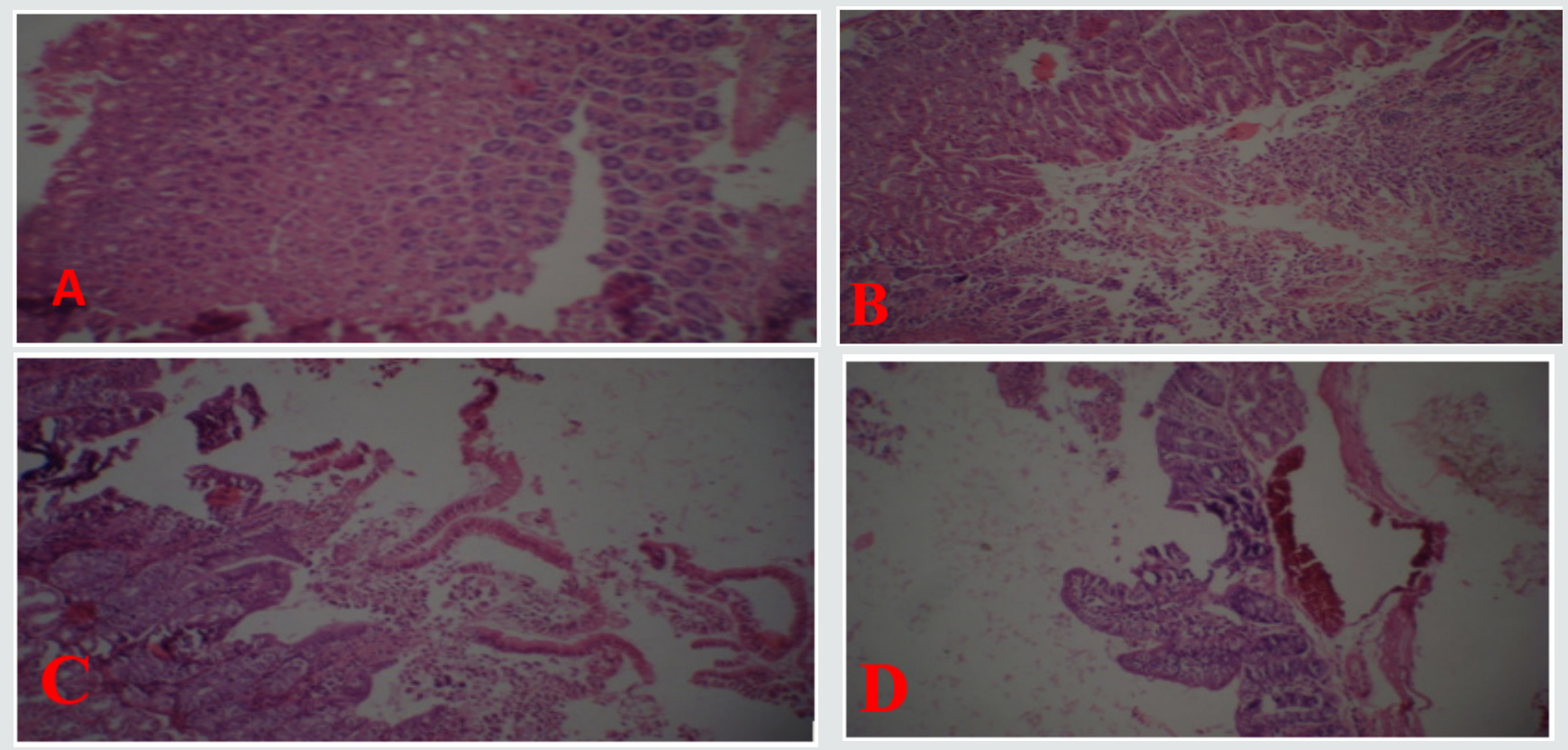

Figure 1: Light photomicrographs (10× magnifications) of hematoxylin and eosin- stained sections of stomach.

A: Normal gastric mucosa.

B, C: Ethanol treated stomach with Exfoliation and sloughing of gastric cells.

D: Ethanol treated with congestion of blood vessel. 

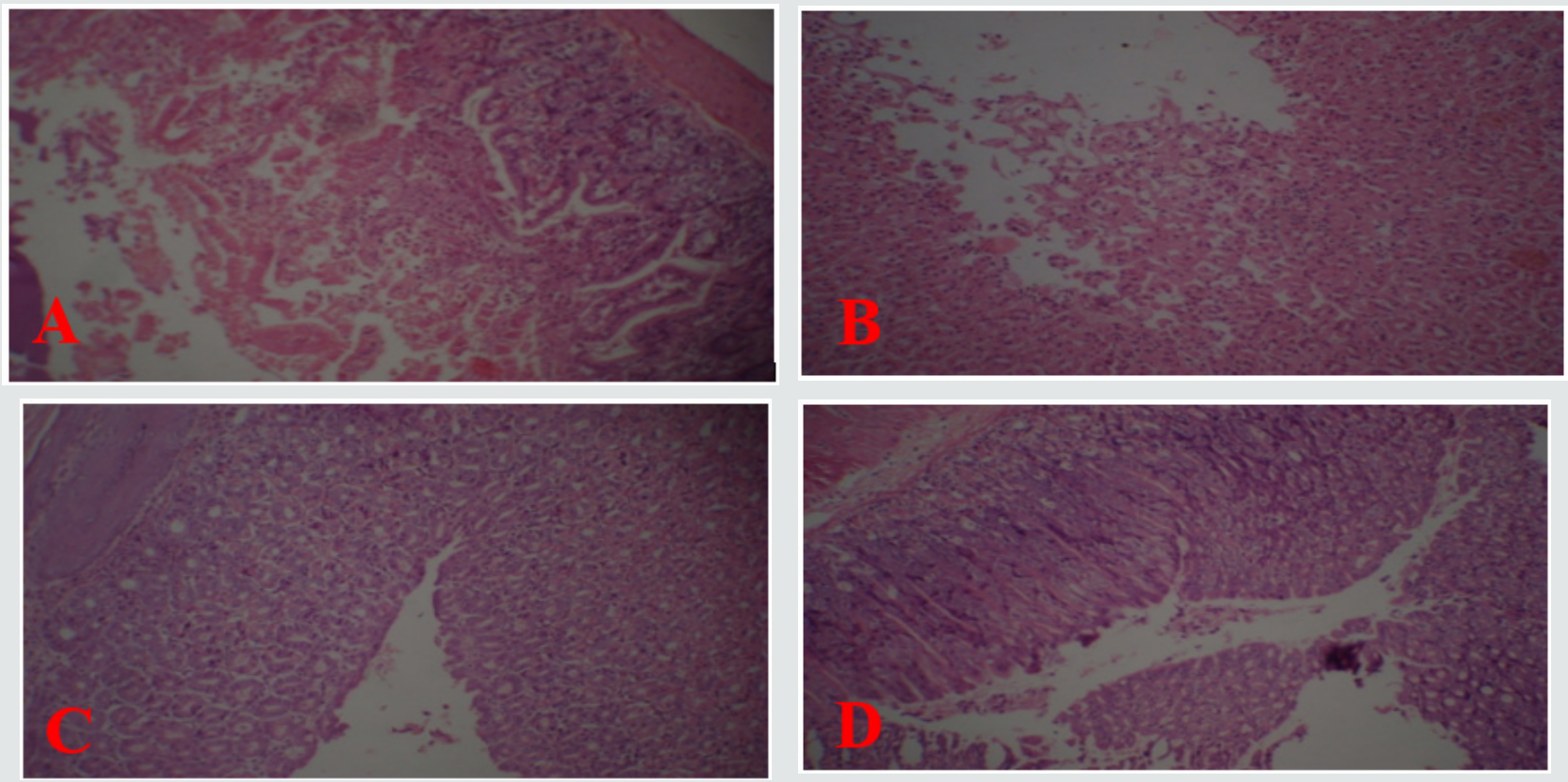

Figure 2: Light photomicrographs(10×magnifications) of hematoxylin and eosin-stained sections of stomach:

A: Ginger treated (IP) stomach.

B: Ginger treated (IP) stomach.

C: Chronic ginger treated (IP).

D: Ranitidine treated (IP) stomach.

In present paper ethanol administration provoked significant gastric mucosal injuries as evidence by necrosis, exfoliation and sloughing of gastric cells, congestion of blood vessels and infiltration of inflammatory cells. Cytoprotective action of ginger has been investigated using animal models of acute gastric injury induced by necrotizing agents such as ethanol. Ethanol serves as the most common ulcerogenic agent and produced sever gastric hemorrhagic erosions Robert et al. [12]; Szabo et al. [13]. The genesis of ethanol-induced gastric lesions is multifactorial with the depletion of gastric wall mucus content as one of the involved factors. Submucosal venular constriction by ethanol and eventual injury is caused due to perturbations of superficial mucosal cells, notably the mucosal mast cells leading to release of vasoactive mediators including histamine, that cause damage to gastric mucosa Hollander et al. [14]. Accumulation of activated neutrophil in gastric mucosa may be the source of free radicals Oxygen free radical which lead to increase to lipid peroxidation and damage to cell membrane are impacted in ethanol induced gastric mucosal injury Al-Harbi et al. [15]. In addition to its direct damage of gastric mucosal cells by development of free radicals, cause solubilization of mucus constituents and depressant tissue levels of protein leading to flow stasis in gastric blood. The present paper revealed parial cytoprotection by single oral dose of ginger $(300 \mathrm{mg} / \mathrm{kg})$ in mice. More effective cytoprotection was elicited by (600 mg/kg I.P).

The results obtained in the present paper indicated that ginger extract possess its anti- ulcerative properties through a mechanism mainly related to acid and pepsin inhibition Chronic I.P injection of plant extract in a dose of $(300 \mathrm{mg} / \mathrm{kg})$ more effective in prevention lesion formation. The mechanism of ginger extract in chronic (I.P) protection may be due to counteracting the active oxidant radicals, decreasing mucosal cell shedding and thicking the mucus membrane. The mechanism of anti-ulcer effect of ginger may be due to presence of 6-Gingersulfonic acid and three monoacyldigalactosyl gylcerols including ginger glycolipid A. B. C have been isolated from dried rhizome of Zingiber Officinale which are potent anti-ulcer components Yoshikawa et al.[16]. 6- Gingerol and 6- shogaol are two other anti- ulcer components that are less potent but are mainly responsible for ginger pungency. The results of present paper in accordance with previous reports in which water and methanolic extract of eight Zingiberaceae herbs caused a significant decrease in gastric secretion in un-anesthetized rabbits and the effect of water extract was similar to cimetidine Sakai et al. [17].

\section{References}

1. Ali BHG, Blunden, Tanira MO, A Nemmar (2007) Some phytochemical, pharmacological and toxicology properties of ginger (Zingiber officinale) review of recent research. Food Chem Toxicol 18: 17950516.

2. AL-Harbi MM, Quershi S, Raza M, Ahmed MM, Afzal Ma, et al. (1997) Gastric anti-ulcer and cytoprotective effect of Commiphora Molmol in rats. J Ethanopharmacol 55:14150.

3. Al-Yahya MA, Rafatuallah S, Mossa JS, Ageel AM, Parmar NS, et al. (1989) Gastroprotective activity of ginger in albino rats. American Journal of chinese Medicine 17(1-2): 51-56. 
4. Barroman JA, P Feiffer GJ (1982) Cabenoxolone: Acritical analysis of its value in peptic ulcer. Drugs and peptic ulcer. Boca Raton 123-132.

5. Goel RK, Chakrabarthy A, Sanyal AK (1985) The effect of biological variable on the anti-ulcerogenic effect of vegetable plantain banana planta Media. 2: 85-88.

6. Hollander D, Taranawski A, Gergely H, Zipser KD (1984) Sucralfate protection of the gastric mucosa against alcohol-induced injury: A prostaglandin-mediated process. Scand J Gastrooenterol 101: 97-102.

7. (2002) Iranian Herbal Pharmacopea Scientific Committee Iranian Herbal Pharmacopeia. ( $1^{\text {st }}$ edn), Iranian Ministry of Health publication, Iran 25.

8. Langmead L, Rampton DS (2001) Herbal treatment in gastrointestinal and liver disease-benefit and danger. Aliment Pharmacol Ther 5: 12391252 .

9. Miniaiyan MA, Ghannadi A, Karimzaadeh (2006) Anti-ulcerogenic effect of ginger (rhizome of Zingiber officinale Roscoe) on cysteamine-induced duodenal ulcer in rats. 14(2): 97-101.

10. Robert A, Nezamis JE, Lancaster C, Hanchar AJ (1979) Cytoprotective by prostaglandins in rats. Prevention of gastric necrosis produced by alcohol, $\mathrm{HCL}, \mathrm{NaOH}$, Hypertonic NaCL, and thermal injury. Gastroenterology 777 433-443.
11. Sakai K (2989) Effect of extract of Zingiberaceae herbs on gastric secretion in rabbits. Chem Pharm Bull 37: 215-217.

12. Shetty R, Kumar KV, Naidu MUR, Ratnakar KS (2000) Effect of Gingko biloboba extract on ethanol-induced gastric lesions in rats. Indian $\mathrm{j}$ pharmacol 32-32: 313-317.

13. Sertiej AA (1992). Preventive anti-ulcer activity of the rhizome extract of Zingiber officinale. Fitoterpia 63: 55-59.

14. Szabo S, Trier JS, Frankel PW (1981) Sulfhydryl compounds may mediate gastric cytoprotection. Science 214: 200-202.

15. Villegas I, LaCasa C, de La Lastra CA, Motilva V, Herreri JM, et al. (2004) Mucosal damage induced by COX-1 and COX-2 inhibitors: Role of prostaglandina and inflammatory response. Life Sci 74: 873-884.

16. Wallace JL (1996) NSAID gastroenteropathy: past, present, future. Can j Gastroenterol 10 451-549.

17. Yoshikawa M, Yamaguchi S, Kunimi K, Matsuda H, Okuno Y, et al. (1992) 6-gingersulfonic acid, a new anti-ulcer principle. And ginger glycolipid A $\mathrm{B}, \mathrm{C}$, three new monoacyldiagalactosylglycerols from Zingiberis rhizome originating in Taiwan. Chem Pharm Bull 40: 2239-2241.

\section{(c) (1) \\ This work is licensed under Creative \\ Commons Attribution 4.0 License}

To Submit Your Article Click Here:

Submit Article

DOI: $10.32474 / O A J C A M .2020 .02 .000139$

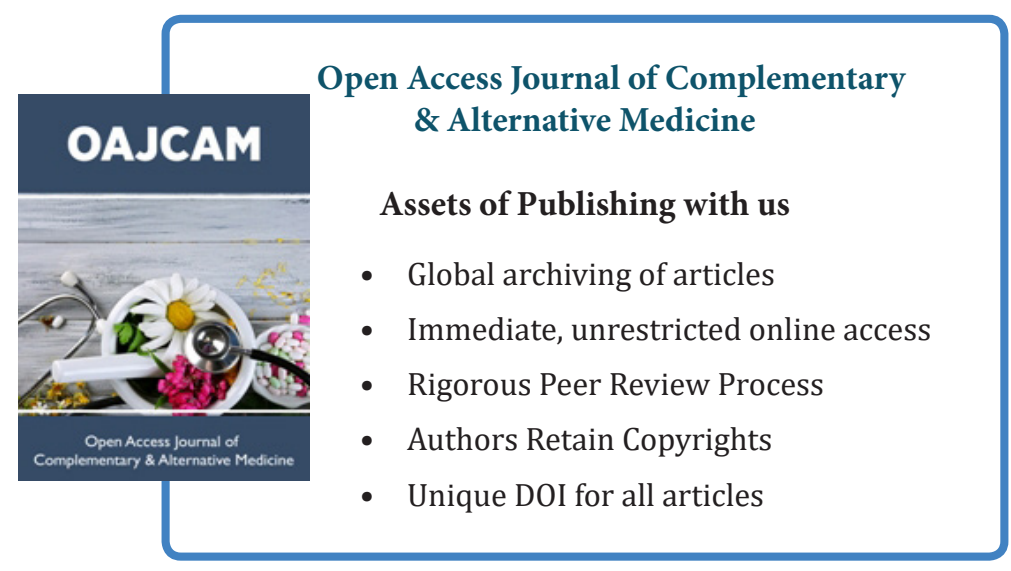

